\title{
Preliminary verification results of the DWD limited area model LME and evaluation of its storm forecasting skill over the area of Cyprus
}

\author{
A. Orphanou ${ }^{1}$, S. Michaelides ${ }^{1}$, K. Savvidou ${ }^{1}$, P. Constantinides ${ }^{1}$, J.-P. Schulz ${ }^{2}$, and U. Voigt ${ }^{2}$ \\ ${ }^{1}$ Meteorological Service, Nicosia, Cyprus \\ ${ }^{2}$ Deutscher Wetterdienst (DWD), Offenbach am Main, Germany
}

Received: 11 November 2005 - Revised: 7 January 2006 - Accepted: 11 January 2006 - Published: 22 February 2006

\begin{abstract}
A preliminary verification and evaluation is made of the forecast fields of the non-hydrostatic limited area model LME of the German Weather Service (DWD), for a recent three month period. For this purpose, observations from two synoptic stations in Cyprus are utilized. In addition, days with depressions over the area were selected in order to evaluate the model's forecast skill in storm forecasting.
\end{abstract}

\section{Introduction}

The local model LME (Doms and Schättler, 2002; Steppeler et al., 2003; Schulz, 2005) was developed by the German Weather Service (DWD). Its pre-operational phase started in January 2005 and in September 2005 it became operational. The boundary data for the LME are provided by the operational global model GME every hour. The horizontal resolution of the LME is $7 \mathrm{~km}\left(0.0625^{\circ}\right)$, while the atmosphere is represented by 40 layers in the vertical (ten of which resolve the boundary layer structure). The LME covers the whole European region, including the Mediterranean, Black, North and Baltic Seas. For the purpose of this study, a sub-area was chosen, enclosed by meridians $20^{\circ} \mathrm{E}$ and $37^{\circ} \mathrm{E}$ and latitude circles $30^{\circ} \mathrm{N}$ and $40^{\circ} \mathrm{N}$.

\section{Data and methodology}

The parameters used in the verification are the surface pressure (MSLP), $2 \mathrm{~m}$ temperature (T), dew-point temperature (Td) and the eastward and northward components of wind at $10 \mathrm{~m}$ ( $\mathrm{u}$ and $\mathrm{v}$, respectively). Observed and forecast values for these parameters at lead times $t+0, t+06, t+12, \ldots, t+72$ are compared (thirteen lead times for each model run).

The observations were made by two Automatic Weather Observing Systems located at the airports of Larnaca $\left(33.37^{\circ} \mathrm{E}, 34.52^{\circ} \mathrm{N}\right)$ and Paphos $\left(32.49^{\circ} \mathrm{E}, 34.72^{\circ} \mathrm{N}\right)$, for a three-month period from 1 February to 30 April, 2005.

From the model output, values at 12 grid points surrounding each station (as shown in Fig. 1) were extracted and used in the verification. The two model runs (00:00 UTC and 12:00 UTC) were studied separately.

To estimate the forecast values at each station, a time, $p a-$ rameter and site dependent weighted average interpolation procedure was adopted. For each of the forecast times in the first $24 \mathrm{~h}$ forecast period and for all the model runs in the study period (00:00 UTC and 12:00 UTC runs were treated separately), the absolute error between the observed value at the station and the corresponding forecasts at each of its surrounding grid points was calculated. The corresponding weight for each grid point is considered to be proportional to the percentage of times that a grid point's absolute error was minimum (i.e. grid points approximating better the station value bear a higher weight). Different weights were calculated for each of the meteorological parameters (see Fig. 2).

The following two measures were used in the verification: Mean Error (ME) and Mean Absolute Error (MAE).

\section{Results}

In this section, the verification measures for each of the parameters investigated are presented. The verification measures for each parameter and for various forecast times are shown in Fig. 3 (Larnaca) and Fig. 4 (Paphos). 

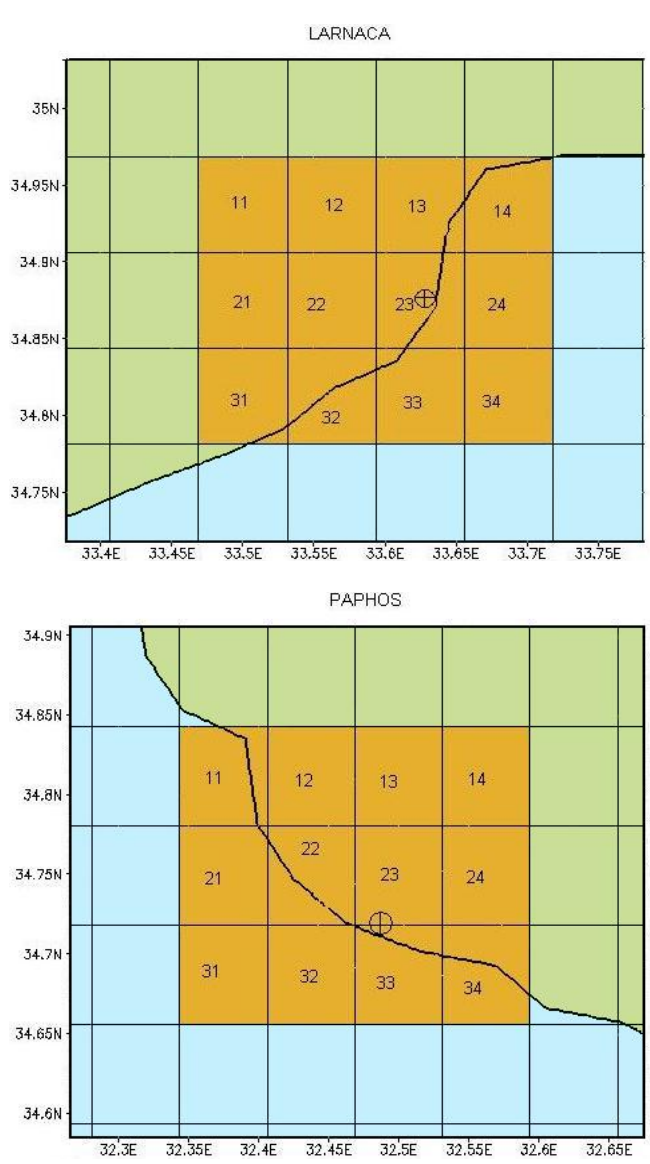

Fig. 1. Verification for Larnaca and Paphos airports: marked boxes indicate the model grid boxes considered in the verification and circled-crosses the corresponding stations.

\section{$3.12 \mathrm{~m}$ Temperature $\left(\mathrm{T}-{ }^{\circ} \mathrm{C}\right)$}

Overall, $\mathrm{T}$ is overestimated by the model at Larnaca, by about $0.8^{\circ} \mathrm{C}$ (from the ME curve). Also, for Larnaca, a 24-h cyclic behavior of the ME is noted. This characterizes both the 00:00 UTC and 12:00 UTC model runs. The maximum overestimation is noted at $\mathrm{t}+0, \mathrm{t}+24, \mathrm{t}+48$ and $\mathrm{t}+72$ of 00:00 UTC run and at $t+12, t+36$ and $t+60$ of 12:00 UTC. This overestimation refers to $\mathrm{T}$ at 00:00 UTC, for both model runs. An underestimation is noted at $t+06, t+30$ and $t+54$ for 00:00 UTC model run and at $\mathrm{t}+18, \mathrm{t}+42$ and $\mathrm{t}+66$ for 12:00 UTC model run, which both refer to 06:00 UTC. It is worth mentioning that the errors are approximately constant with increasing lead time.

In contrast to Larnaca, Paphos forecasts exhibit an overall underestimation by around $0.8^{\circ} \mathrm{C}$. Again, a 24-h cyclic behavior is noted, but with smaller wave amplitude. The mean error of T takes the highest values of MAE at 00:00 UTC by both model runs (at $t+0, t+24, t+48$ and $t+72$ from 00:00 UTC run and at $t+12, t+36$ and $t+60$ from 12:00 UTC). The maximum underestimation occurs again at 06:00 UTC by both model runs $(\mathrm{t}+06, \mathrm{t}+30, \mathrm{t}+54$ for 00:00 UTC model run and at $\mathrm{t}+18, \mathrm{t}+42, \mathrm{t}+66$ for 12:00 UTC).
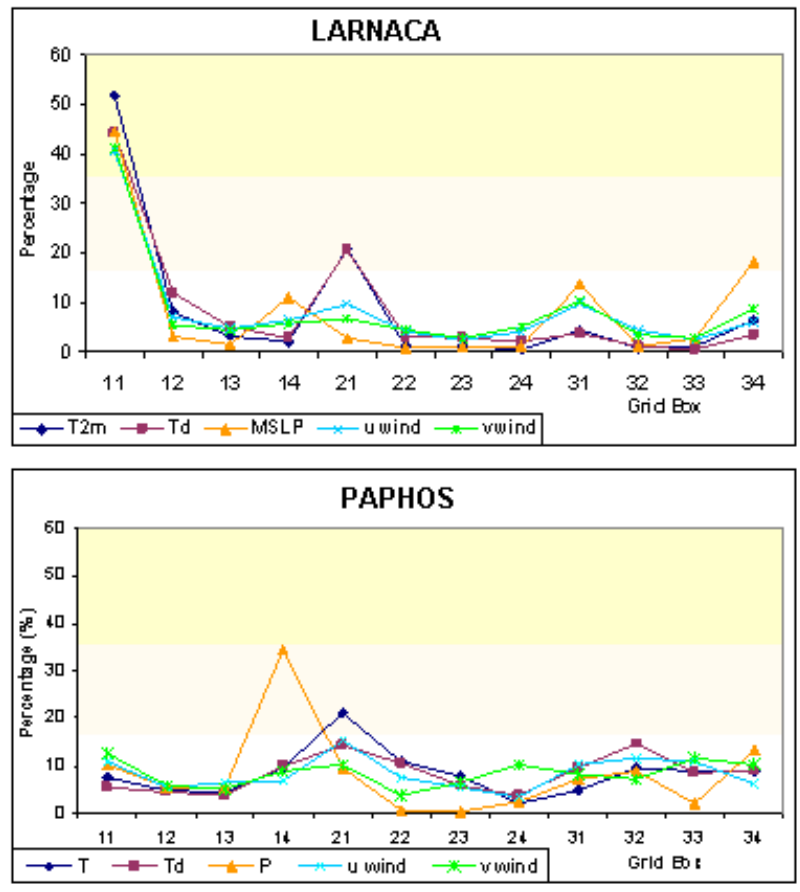

Fig. 2. Representativeness of each grid box, expressed as a percentage (refer to Fig. 1 for grid box indices), for Larnaca (top) and Paphos (bottom) for the 00:00 UTC run of the model.

\subsection{Dew-point Temperature $\left(\mathrm{Td}-{ }^{\circ} \mathrm{C}\right)$}

Regarding the forecasts for Dew-point temperature, very similar results were found as for $\mathrm{T}$. The overestimation at Larnaca is around $1.1^{\circ} \mathrm{C}$ and at Paphos $0.9^{\circ} \mathrm{C}$.

\subsection{Mean Sea Level Pressure (MSLP - hPa)}

A continuous underestimation of the MSLP is noted for both 00:00 UTC and 12:00 UTC model runs, at both Larnaca and Paphos. This underestimation is small: for the majority of the cases does not exceed $1 \mathrm{hPa}$. An increase of the ME though, is noted in the forecasting period from $t+06$ till $t+18$ from the 00:00 UTC runs for both Larnaca and Paphos. The forecast is again improved after $t+24$. Within this forecast period, the underestimation of the atmospheric pressure reaches $1.5 \mathrm{hPa}$.

\subsection{Wind components $(\mathrm{u}, \mathrm{v}-\mathrm{m} / \mathrm{s})$}

An overall underestimation of the u-wind component at Larnaca airport is found with both 00:00 UTC and 12:00 UTC model runs. The mean error is very small and in many cases close to zero. Concerning the v-wind component, a remarkable 24-h cyclic behavior of the ME is noted. In most cases, this parameter is underestimated, having the maximum underestimation every 24-h. This refers to the forecast times $t+06, t+30$ and $t+54$ of the 00:00 UTC run and $t+18, t+42$ and $t+66$ for 12:00 UTC run. All the aforementioned forecast times represent 06:00 UTC of the corresponding day. The 

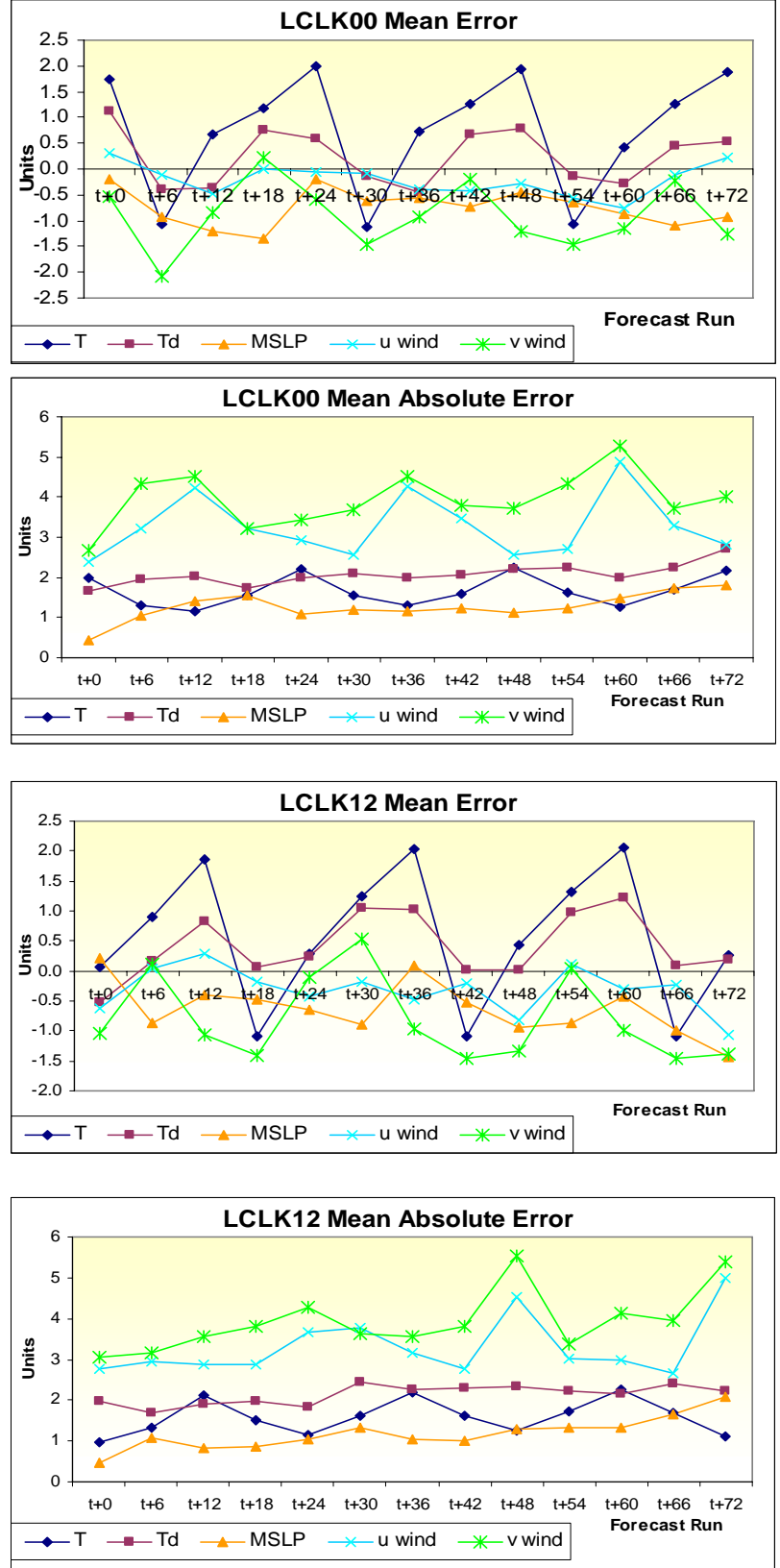

Fig. 3. Verification measures for Larnaca for various forecast times. Model runs for 00:00 UTC and 12:00 UTC.

maximum peaks of the curves of ME are noted $12 \mathrm{~h}$ after the minima, that is, $t+18, t+42$ and $t+66$ for 00:00 UTC run and $t+06, t+30$ and $t+54$ of the 12:00 UTC run, all referring to 18:00 UTC of the corresponding day.

A not so explicit picture of the behavior of the two wind components was found for Paphos. In general, the ME of ucomponent varies from -0.5 to $+0.5 \mathrm{~m} / \mathrm{s}$. The ME curve of the $\mathrm{v}$-wind component shows a decreasing trend with some perturbations, which is related to an increase of the underestimation of the values of $\mathrm{v}$-wind component.
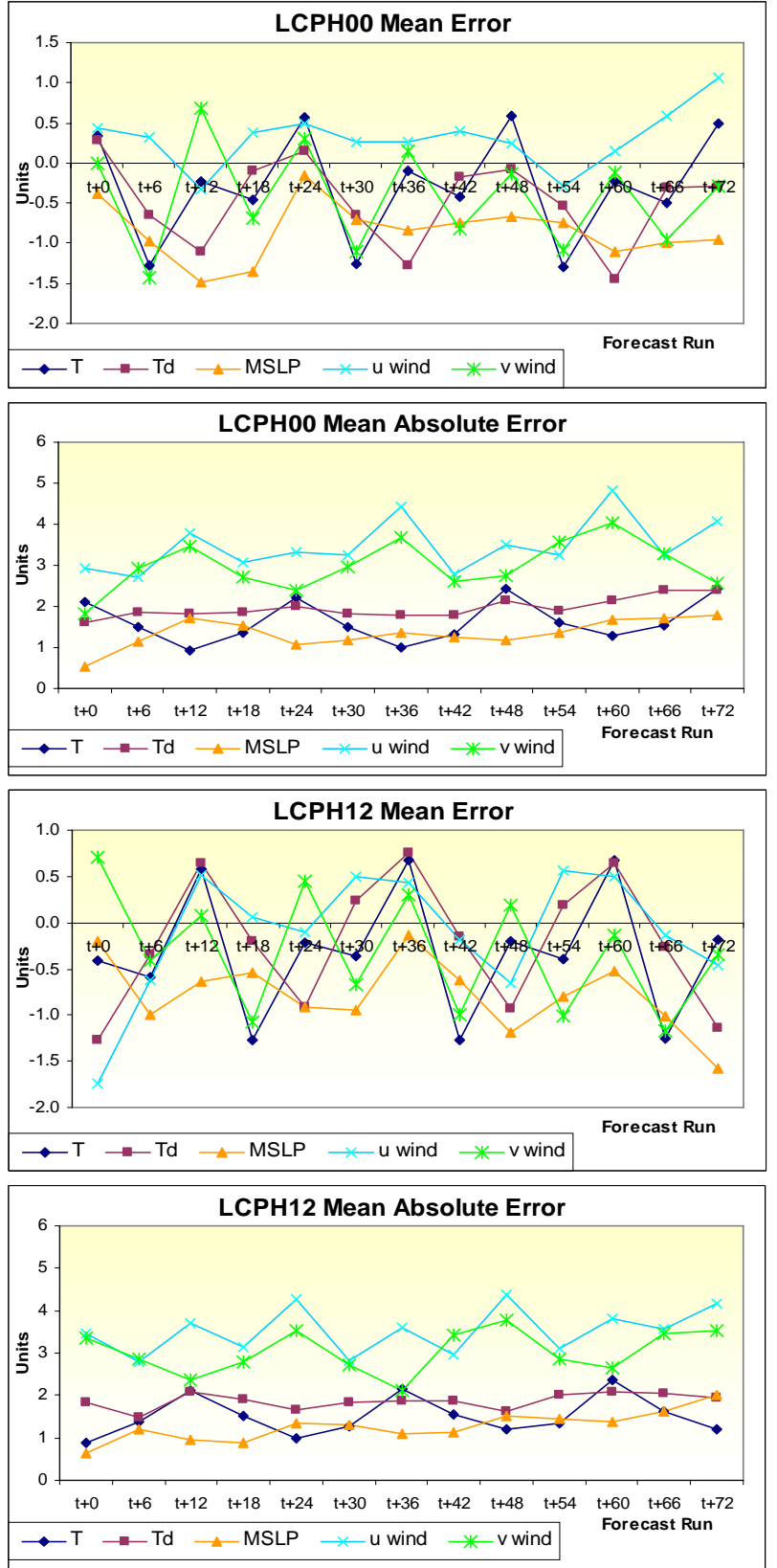

Fig. 4. Verification measures for Paphos for various forecast times. Model runs for 00:00 UTC and 12:00 UTC.

\section{Storm forecast skill}

During the winter period, the area of Cyprus is quite frequently affected by cyclonic systems (see Meteorological Office, 1962; Reiter, 1975; Flocas et al., 2001; Michaelides et al., 2004; Nicolaides et al., 2004) that influence the weather of the whole eastern Mediterranean. Therefore, it is interesting to investigate the skill of the model in predicting such systems.

During the three month study period, eleven cases of depressions were recorded over Cyprus, three of which were well organized giving thunderstorms, showers, hail and 


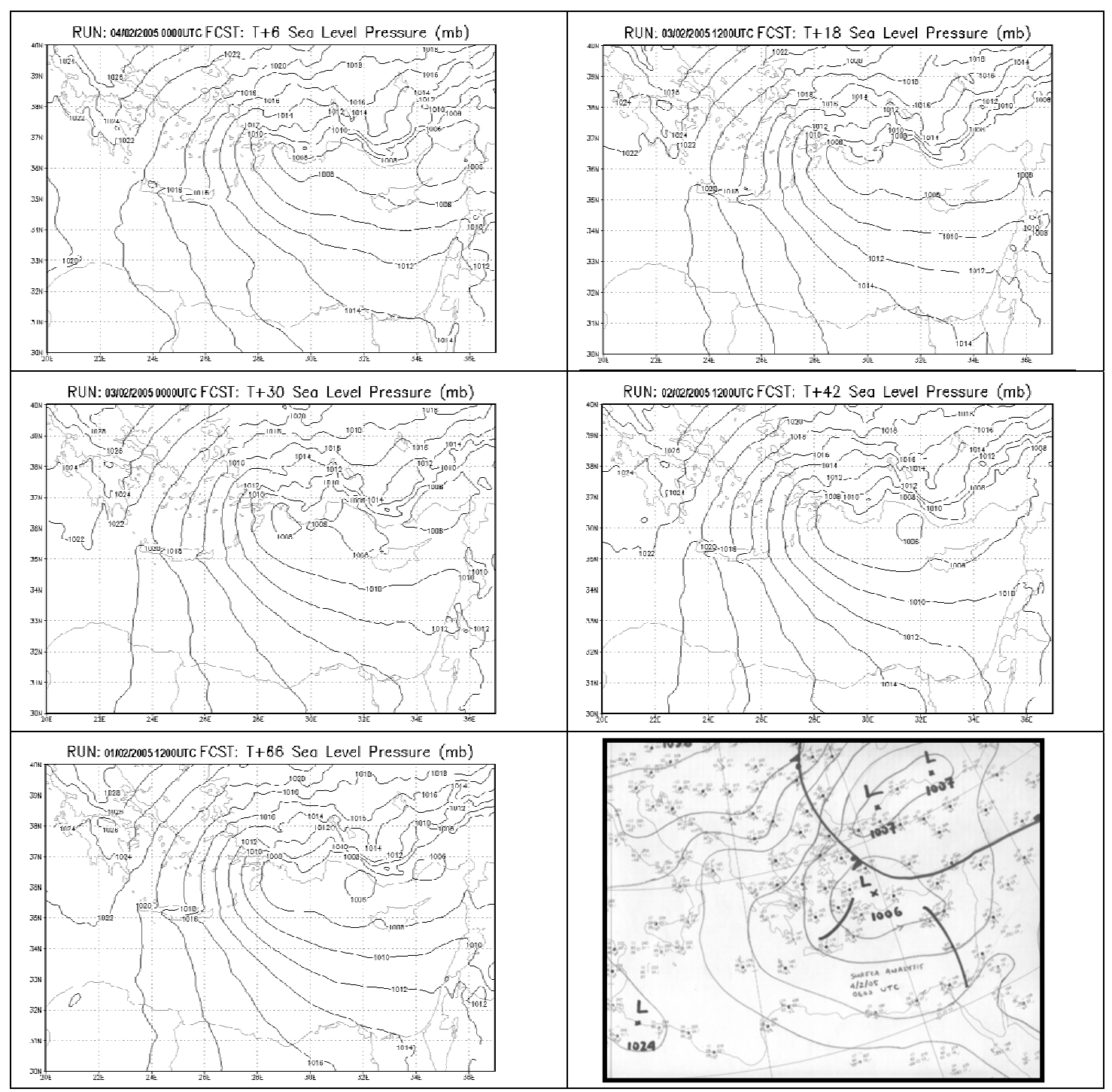

Fig. 5. Forecast Mean Sea Level Pressure charts for 4 February 2005 06:00 UTC from consecutive model runs (marked appropriately) and the corresponding actual analysis chart for the same time (right lower corner).

strong winds; in the other eight cases, the above weather phenomena were isolated and less intense.

The forecast surface charts of the LME were contrasted to the respective actual surface charts analyzed by the Meteorological Service of Cyprus. Four features of the depressions have been checked: the pressure value at the center of the depression, the movement of the center of the depression, the orientation and the position of the pressure field in the area of Cyprus and the lead time that the depressions were identified by the model.

From the eleven depressions, four of them were predicted $72 \mathrm{~h}$ in advance $(\mathrm{t}+72$ of the model run that referred to the time of interest), two of them $66 \mathrm{~h}$, one of them $48 \mathrm{~h}$, one $42 \mathrm{~h}$ in advance and one was not forecast at all. Two depressions could not be verified due to lack of model data.

\section{A case study}

Although for all depressions studied, a detailed documentation was kept in order to investigate the forecast skill of the model in predicting them, only one such event is discussed here. This case study refers to a depression with its maximum deepening on the $4 / 2 / 2005$.

At 00:00 UTC of 3 February 2005, a cyclonic circulation centered over the Aegean Sea is noted, with a central pressure of $1001 \mathrm{hPa}$. The depression moved eastwards with further deepening till 12:00 UTC and begun to fill thereafter. The track of the centre was to the north of Cyprus between 18:00 UTC on 3 February 2005 and 00:00 UTC on 5 February 2005. The pressure over the area of Cyprus fell till 12:00 UTC of 4 February 2005, where the lowest value noted was $1007 \mathrm{hPa}$. Thereafter, the surface pressure begun rising. 
Table 1. Differences between the forecast values of the five studied parameters and their actual values (ACT), for the depression on the 4 February 2005 06:00 UTC, at Larnaca (LK) and Paphos (PH).

\begin{tabular}{ccccccccccc}
\hline & \multicolumn{2}{c}{ T } & \multicolumn{2}{c}{ Td } & \multicolumn{2}{c}{ MSLP } & \multicolumn{2}{c}{ u } & \multicolumn{2}{c}{$\mathrm{v}$} \\
\hline Time & LK & PH & LK & PH & LK & PH & LK & PH & LK & PH \\
\hline ACT & 15.7 & 16.0 & 10.2 & 11.6 & 1008.1 & 1008.9 & 2.3 & 8.5 & -1.9 & -3.1 \\
$\mathrm{t}+6$ & -1.0 & -2.2 & -0.8 & -1.1 & -0.3 & -0.2 & 7.9 & 6.2 & 7.5 & 3.6 \\
$\mathrm{t}+18$ & 5.5 & -2.6 & 4.9 & 0.3 & 2.9 & -0.4 & 2.4 & 4.8 & 4.2 & 3.7 \\
$\mathrm{t}+30$ & 5.6 & -2.6 & 8.2 & -0.9 & 2.3 & 0.3 & 7.7 & 3.7 & 5.1 & 8.0 \\
$\mathrm{t}+42$ & -1.1 & -2.5 & 0.0 & -1.5 & -0.2 & -1.1 & 8.4 & 3.6 & 0.0 & 8.4 \\
$\mathrm{t}+54$ & -1.4 & -2.9 & 0.4 & -1.1 & -0.4 & -0.6 & 2.6 & 3.0 & 11.0 & 7.1 \\
$\mathrm{t}+66$ & -0.6 & --2.4 & 1.2 & 0.0 & -0.5 & -0.7 & 11.7 & 6.3 & 11.9 & 6.9 \\
\hline
\end{tabular}

The LME forecast output (see Fig. 5) showed that the synoptic situation for this depression was predicted $42 \mathrm{~h}$ in advance $(\mathrm{t}+42 \mathrm{~h}$ lead time, from the 00:00 UTC model run of 1 February 2005). The central pressure values were underestimated by $2-4 \mathrm{hPa}$ in the following model runs, but the maximum underestimation of pressure values noted over Cyprus was $5 \mathrm{hPa}$. Concerning the positioning of the centre of the depression, the comparisons showed a slight misplacement of $1-2^{\circ}$ northwards and $1-2^{\circ}$ eastwards.

A verification of the model output with regard to this case study by using Larnaca and Paphos stations was made and the results are shown in Table 1 . The differences between the forecast values by the LME and the actual ones are found not to follow any particular trend with increasing lead time. For example, in the case of $\mathrm{T}$ at Paphos, a continuous underestimation of the parameter was noted, with an improvement as the lead time becomes closer to the actual time.

On the contrary, at Larnaca both an underestimation and an overestimation within the different model runs were noted. In addition, the best prediction was made by the model run with lead time $t+66$. It is worth noting though, that the $t+42$ and $\mathrm{t}+54$ lead times provided better forecasts than at $\mathrm{t}+18$ and $\mathrm{t}+30$. A possible reason for this is that the processes taking place during the data assimilation require a stabilizing period and therefore the forecasts referring to lead times closer to the actual time are not so representative.

\section{Concluding remarks and future work}

In this study, some preliminary results have been presented concerning the verification of the LME in the Eastern Mediterranean. This is the first effort made for the preoperational model LME in this area and it has already contributed and will further contribute to the development of the model when having set it as an operational tool.

For both stations, an increase of the error is noted with increasing lead time. At Larnaca, T and Td were found to be overestimated by LME, while MSLP and the v-wind component were underestimated. At Paphos, an overestimation of the $\mathrm{u}$-wind component was found and an underestimation of the rest of the parameters studied. In many cases, the aforementioned errors have a 24-h cyclic behavior.

Also, the MSLP forecast by the model is found to be stabilized after $\mathrm{t}+18$, having minimum errors during the forecasting period from $\mathrm{t}+24$ till $\mathrm{t}+54$.

Concerning the forecast skill of the model to predict cyclonic systems, it was found that the pressure field was, in general, well predicted by the model with a small misplacement of the center of the respective depression.

A preliminary verification for precipitation was also carried out but, bearing in mind the spatial characteristics of this parameter it was decided that a denser network of stations is needed and the verification of this parameter was left for future investigation.

An interpolation procedure was adopted which is time, $p a-$ rameter and site dependent. Because of the way it is used in the present context, the verification is biased, to some extent. However, when more data become available, the methodology will be tested with independent data.

It is obvious that the verification presented here is still not rigid but more work is needed in this direction. In the near future the following goals have been set:

- It is planned to increase the number of stations used in the verification, extending the verification over the mountainous area. Regarding precipitation, in particular, this is of crucial importance, since only a dense network of stations can be considered as representative of its spatial character.

- The study period will be extended for at least one year, so that seasonal comparisons can be made possible.

- Once a significant number of synoptic situations is collected, more trustworthy results will be derived.

- Comparison of the LME with the global model of the DWD is planned. By contrasting the two models, a comparative evaluation of the performance of the local model LME will be made over the area of Cyprus. 
Edited by: V. Kotroni and K. Lagouvardos

Reviewed by: anonymous referee

\section{References}

Doms, G. and Schättler, U.: A description of the nonhydrostatic regional model LM. Part I: Dynamics and Numerics, Deutscher Wetterdienst, Offenbach, 134 pp., available at: www. cosmo-model.org, 2002.

Flocas, H. A., Maheras, P., Karacostas, T. S., Patrikas, I., and Anagnostopoulou, C.: A 40-year Climatological study of relative vorticity distribution over the Mediterranean, Int. J. Climatol., 21, 1759-1778, 2001.

Meteorological Office: Weather in the Mediterranean, Vol. I, 2nd edition, HMSO, London, 1962.
Michaelides, S. C., Nicolaides, K., and Karacostas, T.: Statistical characteristics of the cold season depressions over the area of Cyprus, Meteorologický Èasopis, 7, 61-66, 2004.

Nicolaides, K., Michaelides, S. C., and Karacostas, T.: Spatial distribution of some dynamic parameters during the evolution of selected depressions over the area of Cyprus, Int. J. Climatol., 24, 1829-1844, 2004.

Reiter, E. R.: Handbook for forecasters in the Mediterranean, Naval Postgraduate School, Monterey, California, USA, 1975.

Schulz, J.-P.: Introducing the Lokal-Modell LME at the German Weather Service, COSMO Newsletter, 5, 158-159, available at: www.cosmo-model.org, 2005.

Steppeler, J., Doms, G., Schättler, U., Bitzer, H. W., Gassmann, A., Damrath, U., and Gregoric, G.: Meso-gamma scale forecasts using the nonhydrostatic model LM, Meteor. Atm. Phys., 82, 7596, 2003. 